\title{
Construcción de identidades colectivas entre inmigrantes: ¿interés, reconocimiento y/o refugio?
}

\author{
Nuria del Olmo Vicén \\ Universidad Pública de Navarra \\ nuria.olmo@unavarra.es
}

RESUMEN

La intención de este artículo es establecer un marco de análisis válido para encontrar una respuesta al porqué de la construcción identitaria entre inmigrantes. Para ello reflexionaremos a través de aquellos trabajos que contemplan los procesos de formación de identidades colectivas en diferentes tradiciones teóricas, y cuya literatura se nutre principalmente de los estudios sobre la acción colectiva y los trabajos sobre etnicidad, incluyendo en estos últimos aquellos trabajos orientados a la explicación del resurgir étnico contemporáneo. Concluimos el artículo extrayendo tres posibles paradigmas para explicar el porqué de la formación de identidades colectivas entre inmigrantes: Primero, el paradigma racionalista que explica la construcción de identidades en función de la existencia de unos intereses comunes. Segundo, el paradigma de representación que explica la construcción identitaria como vía de reconocimiento que permite la participación del colectivo inmigrante en el sistema de la sociedad de acogida. Tercero, el paradigma del refugio psicológico para explicar la construcción identitaria como respuesta a una situación de desarraigo, consecuencia del proceso migratorio. La hipótesis principal es que la construcción identitaria en el seno de colectivos de origen inmigrante encuentra su razón en la búsqueda de reconocimiento dentro de la sociedad de acogida.

Palabras clave: Identidad Colectiva, Inmigrantes, Identidad Étnica. 


\section{INTRODUCCIÓN}

La identidad, como resultado de un proceso social con carácter dinámico y temporal, se desarrolla en un contexto específico a través de las relaciones entre los individuos. El análisis de este proceso de formación de identidades colectivas requiere considerar la dimensión social y la dimensión simbólica de dicha identidad. Es decir, contemplar las relaciones existentes entre el sistema social en el que se define una identidad y el sistema cultural a través del cual se manifiesta. Si el análisis de las relaciones establecidas en la estructura social nos da una explicación del porqué se forma una identidad, la dimensión simbólica o cultural nos pone de manifiesto el campo semántico de esa identidad, su significado y sus últimas aspiraciones. Estas manifestaciones culturales nos explican el “cómo» se forma, indicándonos la orientación de dicha identidad y estableciendo las fronteras de grupo.

Nuestro objetivo primordial en estas páginas es encontrar una explicación de su formación, ese «porqué» se desarrollan identidades colectivas entre inmigrantes: ¿es la identificación con una identidad colectiva un acto racional y reflexivo?; ¿o reactivo, sin premeditación?; ¿qué persigue como fin último una identidad colectiva entre inmigrantes?; ¿por qué se desarrolla y en qué circunstancias?

Nuestra hipótesis parte de la idea de que: Primero: efectivamente, el proceso migratorio por razones económicas da lugar a la construcción de identidades colectivas entre individuos que comparten un mismo origen nacional. Segundo: esa identidad desarrollada entre inmigrantes será de tipo primario o natural, dado que se produce una identificación con determinados rasgos étnicos - adscritos por ellos pero transmitidos por la herencia- Tercero: las razones para la construcción de una identidad colectiva en el seno de colectivos de origen inmigrante radican en el desarraigo y vivencias comunes, en la consecución de unos intereses - materiales y simbólicos- y en la obtención de un reconocimiento como colectivo. Siendo este punto el principal porqué a la construcción identitaria: a través de este reconocimiento los miembros de un colectivo inmigrante pueden participar de la estructura social de la cual difieren. Cuarto: esta identidad primaria puede evolucionar hacia formas de identidad cultural en función de los objetivos del colectivo.

A pesar de la importancia social que tienen los procesos de formación de identidades colectivas, salvo extrañas excepciones, su estudio nace en el seno de otros trabajos. Entre los que más reflexiones le han dedicado están aquellos sobre la acción colectiva, y más en general los estudios sobre los movimientos sociales. Desde otro punto de vista, también han contribuido los trabajos sobre etnicidad, algunos de los cuales, sobre movimientos étnicos, pueden estar considerados entre los primeros citados. Así, a continuación, pasamos 
a analizar estos trabajos con el fin de establecer aquellos paradigmas que puedan dar una explicación para la formación de identidades colectivas entre inmigrantes.

\section{EXPLICACIONES DESDE LOS TRABAJOS SOBRE LA ACCIÓN COLECTIVA}

Si numerosos son los estudios que han tratado las circunstancias que subyacen a los orígenes de la acción colectiva (th. racionalistas, estructuralistas, normativistas, etc.), pocos son aquellos que desde estas teorías han considerado explícitamente la formación de la identidad. A pesar de todo, podemos considerar algunos desarrollos teóricos que nos conducirán a formular una hipótesis sobre nuestro objeto de estudio.

\section{El paradigma racionalista: la identidad en función del interés}

Intentando encontrar una explicación de la formación de la identidad colectiva, el primer paradigma que se deduce de las teorías de la acción colectiva está basado en el interés, es decir, el paradigma racionalista que considera al individuo como un ser racional capacitado para calcular las ganancias y las pérdidas de una elección, intentando obtener grandes logros a un coste personal bajo.

Entre otros estudios sobre la acción colectiva cabe destacar el trabajo de Tilly, quien con su obra From Mobilization to Revolution (Tilly, 1978) distingue cuatro componentes principales de la acción colectiva: «organización», «movilización», «interés común» y «oportunidad». Nos centramos en ese «interés compartido», o más exactamente en el hecho de que la percepción de la existencia de intereses comunes pueda conducir al desarrollo de una identidad colectiva que —a su vez- haga viable la consecución de dichos intereses.

Tras un análisis del concepto de interés en S. Mill, Durkheim, Weber y Marx ${ }^{1}$, y afirmando la relación entre interés a corto y largo plazo como determinantes de la acción colectiva, Tilly defiende la existencia de un «interés colectivo» sobre el cual se plantea cómo determinar qué intereses son importantes y cómo la gente se suma a ellos. Nuestro problema relativo al interés se plantea en similares términos. La existencia de un interés compartido implica que puede ser el origen de la formación de una identidad colectiva.

\footnotetext{
1 Tilly concluye que las principales divergencias entre los autores se producen en la relación que mantienen entre interés y organización; proponiendo dos opciones básicas para identificar el interés de una población. Una dice que el interés nace de las propias acciones y manifestaciones de la población. Mientras que la segunda opción establecida deduce el interés a partir de una análisis general de las relaciones entre interés y posición social (Tilly, 1978: 60-61).
} 
Dentro de las explicaciones racionalistas para entender y predecir la acción colectiva se desarrolla la teoría de movilización de recursos, corriente teórica que durante décadas marcará uno de los dos polos existentes para la investigación sobre los movimientos sociales vividos a partir de los años sesenta ${ }^{2}$. Hechter, basándose en ésta, aporta algunas ideas para explicar la frecuencia de la acción colectiva étnica (Hechter, Friedman y Appelbaum, 1984) $)^{3}$, en donde se destaca la importancia tanto de la elección individual como del rol que juega la organización en inducir a la participación en la acción.

Considerar este nivel individual de análisis condujo, por un lado, a predecir que los individuos sólo participarán de una acción colectiva cuando las expectativas de beneficios sean mayores que los costes de su participación; pero, por otro lado, tiene como efecto presuponer la existencia del «hombre indiferente» —free-rider -4 (Olson, 1968). Es decir, dicha acción colectiva tiene como objetivo obtener unos bienes públicos —nacidos de metas, deseos o gustos individuales; los cuales, como veremos, pueden ser materiales o intereses «ideales»- Ahora bien, dado que los bienes públicos se caracterizan — de acuerdo con Hechter- por ser indivisibles, inevitables y no rivalizables (Hechter et al., 1984: 416-417) con respecto a su consumo, entonces un individuo puede disfrutar de estos bienes públicos sin haber participado en su producción.

Es decir, el efecto inmediato de la teoría racionalista, que nos explica la acción colectiva a través del cálculo de intereses, es la existencia del «hombre indiferente» (Olson, 1968). De aquí que la estratificación social tenga un efecto indirecto en la producción de la acción colectiva, porque operando a través de la solidaridad de grupo y de la organización se puede motivar a la participación en la acción social. Y, así, la acción colectiva ocurrirá en la medida en que el «hombre indiferente» sea prevenido a través de la producción de sanciones y recompensas (Hechter, Friedman y Appelbaum, 1984).

Efectivamente, la mayoría de las críticas - y contribuciones - para evitar el problema del free-rider han mantenido esta orientación iniciada por Gamson sobre la selección de incen-

\footnotetext{
2 El estudio de los movimientos sociales durante décadas tomó diferentes perspectivas en Europa (New Social Movements: protestas nacidas de reivindicaciones en sociedades altamente desarrolladas) y en Estados Unidos (Resource Mobilization Theory: privación y disponibilidad de recursos) (Klandermas, 1989).
}

3 El artículo se centra en la acción colectiva de origen étnico; sin embargo, como aclaran los mismos autores, el análisis se sustenta sobre una teoría general de la acción colectiva (Hechter, Friedman y Appelabaum, 1984). Éste constituirá el comienzo de una serie de críticas y contracríticas a la teoría apoyadas en parte en la teoría estructural que sustenta el modelo de estratificación (Adam, 1984; Hechter y Friedman, 1984; Dickie-Clark, 1984).

4 La lógica de la acción colectiva (Olson, 1968). Nosotros usaremos el término «hombre indiferente» para sustituir el original free-rider, de acuerdo a la traducción realizada por A. L. Bixio, en J. Elster, El Cemento de la Sociedad. Las paradojas del orden social (Barcelona, Ed. Gedisa, 1991). 
tivos que induzcan a la participación en la acción colectiva y que los individuos puedan calcular individualmente (Gamson, 1975, en McAdam, 1988: 136).

Hechter replica —en concreto a las críticas de Adam (1984) — que la producción de ciertos bienes requiere una acción conjunta en la cual los individuos no tienen opción a no cooperar. Así, el concepto de bien público se va matizando a través de estas críticas, incluyendo tanto las materiales como las no materiales, llegándose a distinguir estas últimas entre recompensas sociales —ej., honor y prestigio—y recompensas internas —ej., autogratificación- (Hechter y Friedman, 1984: 385).

Hechter concluye diciendo que los grupos étnicos más presionados o explotados serán los que tengan un mayor interés en obtener beneficios comunes. Pero no sólo es la estratificación social la que tiene una influencia en la producción de solidaridad — dependencia y limitación de oportunidades y capacidad de supervisión son otros factores que, como veremos posteriormente, incrementan la solidaridad-, que evite o contrarreste los efectos del «hombre indiferente».

Las críticas y contracríticas se suceden, pero, evitando alejarnos del tema que nos concierne, podemos preguntarnos si uno de los efectos de una acción colectiva basada en el interés podría ser la formación de una identidad colectiva y, si es así, ¿qué efectos tiene la existencia del free-rider en la formación de dicha identidad colectiva?, ¿qué rol tomarán las incipientes estructuras organizativas —ej., asociaciones de inmigrantes o pro-inmigrantes- en la producción de solidaridad cuya consecuencia sea evitar este fenómeno? Por último, suponiendo -y como posteriormente explicaremos- que a través de la acción colectiva en pos de un interés los individuos desarrollan una identidad colectiva, entonces, ¿se podrá considerar la identidad colectiva como un «bien social» que, debido a sus características de indivisible, no-excluible y no-rivalizable, sea disfrutado por aquellos que participan y que no participan en la acción social? Y si un colectivo desarrolla una identidad colectiva en función de un interés, ¿el tipo de recompensas que se esperan - materiales/no materiales- condicionará la naturaleza y perpetuación de su identidad colectiva?

Una vez que existe un interés común podemos preguntarnos cómo los individuos perciben o se identifican con este interés. Para que se perciba un interés y éste llegue a ser compartido, los individuos deben estar bajo unas mismas circunstancias ${ }^{5}$. Coleman a través de su enfoque racional corrobora la importancia de este punto. A través de su cuestión, «¿qué efecto tiene la identificación para la persona que se identifica con otra, para conducirle a

5 El estar bajo unas circunstancias comunes puede ser fruto de una vivencia o bien puede tener su origen en unas características personales. En cualquier caso, ambas tienen que afectar las relaciones sociales del individuo para generar un interés. 
hacerlo?», es decir a identificarse. Para contestar esto, primero define la identificación como una forma de organización psíquica que tiene fuertes implicaciones en la organización social (Coleman, 1990: 517-519), explicando el proceso de identificación como «una extensión del object self que puede desarrollarse al menos bajo cinco circunstancias»6. Quizás sea la tercera propuesta la más apropiada para contestar a la pregunta anterior, es decir, una persona se identifica con otra cuando ambas han estado (o están) afectadas por los mismos hechos. Es decir, la cuestión no es poseer unas características o vivencias comunes, sino que dichas características afecten al individuo, trastornen su relación social dentro de la estructura en la cual se desenvuelve. Pues esta razón implica una extensión del object self debido a que crea expectativas de beneficios. El individuo se identifica con otros individuos afectados por las mismas circunstancias debido a que a través de su nueva identidad podrá optar a conseguir unos beneficios, es decir, existe un interés compartido.

Por lo tanto, dicha identidad colectiva estará cimentada bajo unas circunstancias comunes que tienen repercusiones en las relaciones sociales de los individuos; de ahí que esta hipótesis — basada en el interés - nos dé una explicación sobre la temporalidad de la identidad: los intereses cambian porque las circunstancias dejan de ser socialmente relevantes.

Cabe preguntarse que en el caso de que esta identidad se desarrolle para la consecución de unos intereses $-\mathrm{y}$ a pesar de ser la identidad temporal en espacio y tiempo, debemos considerar un mínimo de duración-, es decir, si una vez obtenidos dichos intereses, ¿cómo perdura la identidad?

Pizzorno ha hablado de los intereses simbólicos y de los materiales ${ }^{7}$. Mientras que los primeros tienden a perpetuar la identidad, porque refuerzan la solidaridad de grupo, los intereses materiales una vez obtenidos pueden disfrutarse individualmente, sin referencia a una identidad colectiva. Sin embargo, no es tanto el tipo de interés a considerar, sino que dichos intereses tengan un reconocimiento, es decir, constituyan las bases de la representación del grupo. Porque la identidad colectiva puede persistir a través de la renovación de las metas, siempre que los intereses del grupo constituyan las bases de la representación de dicho grupo, sin desaparecer dicha identidad por la pérdida de un objetivo específico. Sin embargo, cuando la identidad colectiva está basada en la ideología y una meta es inalcanzable, la identidad está amenazada (Pizzorno, 1981: 250).

6 Ver Coleman (1990: 517-520).

7 Como vimos, otros autores como Hechter y Friedman también han diferenciado, dentro de las recompensas no materiales, aquellas sociales como son el honor y el prestigio, y las recompensas internas como son la gratificación personal y el martirio (Hechter y Friedman, 1984: 385). 
Se puede establecer una hipótesis para la formación de la identidad colectiva entre inmigrantes basada en el interés: individuos que comparten unas mismas circunstancias -marcadas por la experiencia migratoria-, que afectan a su relación social, desarrollan una identidad colectiva cuyo último objetivo es obtener unos intereses materiales y simbólicos que le sitúe en una situación menos desventajada respecto a otros colectivos insertos en la sociedad de acogida. No obstante, no cerramos aquí su discusión, dado que a raíz de estos trabajos -en ocasiones complementarios y en otras desde una crítica radical- ha surgido una nueva corriente de investigadores que, en su afán de explicar los movimientos sociales acaecidos en la sociedad contemporánea, han desarrollado la contribución -a nuestro entender - más interesante para explicar la formación de una identidad colectiva. Contemplamos dichos estudios agrupándolos en lo que se ha venido definiendo como el paradigma de la acción colectiva orientada al reconocimiento de una identidad.

\section{El paradigma de representación: la identidad en busca del reconocimiento}

Definida la identidad como una «construcción relativamente estable en un continuo proceso de actividad social» (Calhoun, 1991), no se puede dejar de lado la importancia que la estructura social tiene en el desarrollo de este proceso. Varios autores han puesto de manifiesto la diversidad que presentan las sociedades complejas. Las sociedades postindustriales, basadas en el conocimiento, ofrecen una pluralidad de opciones que condicionan la formación de identidades (Holzner, 1983), superponiéndose o entrecruzándose (Nielsen, 1985), poniendo de manifiesto una negociación de las identidades que nos demuestra la existencia de un «elemento voluntarístico» de la identidad (Martellone, 1991) y la existencia de actores sociales que negocian dicha identidad. Sin embargo, no podremos hablar del actor colectivo, negociador de esa identidad, hasta que éste no sea reconocido, es decir, mientras está en la fase de formación (Pizzorno, 1983).

Se define al actor social como la fuente central de la acción y cuya construcción —según las teorías generales de la acción- se desarrolla en una situación de peligro o de «desafío» (Holzner, 1983) ${ }^{8}$. Según Holzner, los actores «nacientes» se caracterizan por una base objetiva mínima y un mínimo sentido de subjetividad, que se ven en circunstancias que implican declarar una identidad, concluyendo que con la creación de una identidad se delimitan a su vez los propios actores sociales (Holzner, 1983). Es decir, a través de la acción emerge una identidad. Si aceptamos esta premisa, la acción es previa a la identidad y dicha acción es delimitada por la identidad emergente. Entonces, en el mundo real, en nues-

\footnotetext{
8 Holzner considera el término «actor social» para referirse tanto al actor colectivo como al individual por considerar que ambos tienen vínculos específicos comunes respecto a la acción.
} 
tro caso práctico, ¿son las acciones delimitadas por la identidad o será que el límite de esa identidad vendrá marcado por las acciones del portador de dicha identidad?

La identidad emerge durante este proceso de acción, según Holzner, pero no demuestra que la acción sea previa a la identidad. En similar sentido, Touraine va un poco más allá. En su estudio sobre la naturaleza de los movimientos sociales en la sociedad moderna -marcada por lo que él denomina la historicidad ${ }^{2}$ - define éstos como la combinación de tres principios: el primero, el principio de identidad; así, considera que la formación de un movimiento precede largamente esta consciencia de identidad, aunque dicho movimiento sólo puede ser organizado con esta consciencia. Para este sociólogo francés, el actor sólo puede defender sus intereses una vez definida su identidad; en caso contrario, el actor no constituirá un grupo de presión y por lo tanto su acción será limitada (Touraine, 1965, 1993). ¿Son estas ideas contradictorias? Todavía queda un poco oscuro si la identidad precede a la acción o viceversa; será Pizzorno quien aporte un poco más de luz a esta discusión. A través de su crítica a las teorías de la acción racional (Pizzorno, 1983) ${ }^{10}$, clasifica algunos tipos de resultados de la acción como «formadores» o «confirmadores» de identidades colectivas. Es decir, efectivamente existen $\operatorname{casos}^{11}$ en los cuales la acción precede a la identidad colectiva; es más, es durante esta acción colectiva cuando tiene lugar la formación de una identidad, porque lo que está en juego en dichos casos de acción colectiva no es la obtención de un determinado beneficio, sino la obtención -o reconocimiento- de una determinada identidad (Pizzorno, 1989: 33) ${ }^{12}$. Son varios los autores que expresan esta característica como peculiar de los nuevos movimientos sociales, explicando éstos bajo el identity oriented paradigm; es decir, los participantes en una acción colectiva persiguen construir una identidad -legitimarla o expresarla - y no el hecho de obtener ciertos intereses objetivos (Cohen, Calhoun, Melucci, Pizzorno, Touraine, etc. ${ }^{13}$.

9 Es decir, los movimientos sociales no pueden entenderse aisladamente; el conocimiento de los procesos sociales se emplea para modificar las condiciones sociales de nuestra existencia.

\footnotetext{
10 Aunque Pizzorno parece contradecirse cuando habla de los confines de la identidad, porque expresa que si una persona actúa lo hace siempre con referencia a una identidad (Pizzorno, 1989: 35), hay que tener en cuenta que en este caso está hablando de un actor individual y los tratamientos son diferentes, la identidad colectiva sí puede surgir en el transcurso de la acción colectiva; es más, esta acción puede pretender el reforzamiento de la solidaridad de grupo a través del reforzamiento de su identidad.
}

11 Sin embargo, Pizzorno deja constancia de que únicamente son algunos tipos de acción colectiva; nosotros estamos de acuerdo en suponer que no toda acción colectiva persigue definir una identidad, sino que, como dice Pizzorno, en aquellos casos en los que en el transcurso de la acción colectiva se produce una identidad es debido a que este era el objetivo porque no se podían calcular los intereses futuros en función de un yo actual (Pizzorno, 1983).

12 Como veremos a continuación, la necesidad de desarrollar esa identidad es debido a que se ha producido una exclusión del grupo y, en sintonía con los argumentos de Touraine, es la única manera de ser reconocido (como dice Touraine, constituirse como grupo de presión), es decir, poder participar en el sistema.

13 Como veremos a lo largo de las siguientes páginas, entre los mencionados autores existen notables diferencias en la explicación de la acción colectiva - y su relación con la identidad— a través del paradigma de la identidad. 
Desde una explicación racional, podemos decir que la identidad colectiva surge en el transcurso de una acción; dicha acción es desarrollada por un colectivo de personas que se encuentra en situación conflictiva, es decir, la identidad surge durante el proceso de respuesta a esa situación. Sin embargo, ello no es suficiente para explicar el porqué es necesaria la formación de una nueva identidad para superar la situación de conflicto, y el porqué dicha acción va encaminada a la formación de una nueva identidad —como formulan los autores anteriormente citados-si en realidad lo que se pretendía era superar la situación de conflicto.

La situación de conflicto puede ser resuelta por la obtención de unos beneficios simbólicos o materiales. De acuerdo con Pizzorno, solamente se definirá a través de la acción colectiva la identidad que se fundamenta sobre «bienes simbólicos» porque la obtención de éstos hará que esta identidad perdure. Sin embargo, aquella que se presenta como exclusiva, es decir, definida a través de bienes materiales, no perdura porque, una vez alcanzados dichos bienes materiales, éstos pueden ser disfrutados individualmente y evaluados en términos de maximización de las utilidades, sin posterior referencia a identidad colectiva alguna. Posteriormente, Pizzorno demuestra que en cualquier caso el problema de la identidad — «los confines de la identidad»— no está en función del tipo de interés a considerar, sino en el reconocimiento que éstos tengan una vez obtenidos (Pizzorno, 1989: 35).

Partimos de que para que se produzca la formación de nuevas identidades colectivas entre inmigrantes tenemos que tener un elemento principal: una categoría de personas con unos intereses determinados — «intereses simbólicos»14_que podrán percibirse y continuarán dando sentido a través de la identidad colectiva, es decir, una colectividad que se comporta como actor social, desarrollando una acción de búsqueda de dichos intereses.

Ahora bien, volvemos a los dos problemas planteados anteriormente. Primero, por qué razón dicha identidad colectiva se desarrolla durante la acción social si, aparentemente, el objetivo de esta acción era obtener unos intereses concretos: aquí la aportación de la crítica de Pizzorno a las teorías de la elección racional, quien resuelve el problema argumentando que el individuo no puede basar su acción social en función del cálculo de unos intereses futuros que son valorados con un «yo» actual. El individuo no tiene una identidad sobre la cual valorar los costes y beneficios futuros; entonces, ¿cómo se puede entender racionalmente su actuación? Según Pizzorno, el objetivo mismo de su acción es la produc-

\footnotetext{
14 Especificamos que nos referimos a intereses simbólicos porque —-según algunos autores como, por ejemplo, Pizzornoéstos una vez alcanzados tienden a perpetuar la identidad colectiva, reforzando la solidaridad del colectivo constituyéndose finalmente como grupo. Porque no olvidemos que nuestra investigación intenta explicar la formación de las identidades colectivas entre inmigrantes dentro del proceso global de la formación de grupo, es decir, de acuerdo con Jackson, el proceso de la formación de la identidad colectiva como el primer proceso en la formación de un grupo (Jackson, 1984).
} 
ción de solidaridad, la premisa para la formación de la identidad colectiva (Pizzorno, 1977: 426). Y, siguiendo con sus razonamientos, sobre la imposibilidad de explicar la acción social en términos de elección racional sostiene que la elección racional exige una valoración de las consecuencias, pero por ello habría que calcular las posibilidades de que los intereses de un «yo» actual coincidan con los de un «yo» futuro ${ }^{15}$.

En tal caso, si no se puede explicar racionalmente la acción social durante la cual se forma la identidad colectiva, ¿cómo se puede entender la acción social? La incertidumbre de las acciones — según Pizzorno- nos viene dada por la inestabilidad que ello representa en el círculo en el cual desarrollamos nuestras acciones, es decir, lo que tenemos que asegurar, según este autor, es la estabilidad, el reconocimiento; esto es lo que busca la acción social: preservar o formar un círculo de reconocimiento (Pizzorno, 1977, 1989) ${ }^{16}$. Porque a través del reconocimiento el actor social podrá entrar en el sistema y defender aquellos intereses, el reconocimiento solamente es posible a través de la identidad, es decir, percibir al otro comprobando su identidad y distinguiéndolo de los demás. Esta explicación puede ser una de las más válidas para la formación de identidades colectivas entre inmigrantes, pero volvamos al problema de la obtención de unos intereses como punto de partida. La explicación anterior implica que en cualquier caso el último fin siempre es la búsqueda de unos intereses por un colectivo, aunque durante la fase de formación de identidad lo único que se realiza es la preparación del terreno para poder solicitar estos intereses, el reconocimiento de dicha identidad y a través de la obtención de estos intereses se mantenga la identidad.

Entonces, cuando se forma una identidad colectiva el último fin que persigue la acción es la disposición para entrar en un sistema o conservar su reconocimiento en el sistema y así poder obtener unos intereses futuros, intereses que hemos denominado simbólicos. Invertimos la explicación para llegar a nuestros objetivos, y diremos que no todos los tipos de acción colectiva conducen a la formación de identidad, con lo cual tendremos que definir la naturaleza de esta acción colectiva. Hasta ahora habíamos hablado de «situación de conflicto o desafío», pero, como veremos a continuación, con el trabajo de Touraine podemos encontrar nuevos orígenes para la emergencia de esa acción colectiva que conduce a la formación de identidades.

Hasta aquí, podemos resumir que todo individuo perteneciente a una colectividad en situación de peligro es un actor social en potencia; como hemos visto, los individuos tienden a

\footnotetext{
15 Anteriormente, Adam, en su crítica a la aplicacion de las teorías racionales para la acción colectiva de carácter étnico, también manifestaba que es imposible estimar los efectos, pero porque los individuos valorarán los costes y beneficios de manera diferente, ya que se apoyan en percepciones individuales (Adam, 1984).

16 Por lo tanto, participar de la acción colectiva es una elección obligada; de esta manera, el dilema del free-rider y las teorías olsonianas de la acción colectiva se han superado.
} 
diseñar confines de máxima eficacia ${ }^{17}$, es decir, se suponen los intereses de la mayoría, y dado que los individuos — como hemos mencionado antes siguiendo a Pizzorno- no tienen opción a no cooperar, desarrollarán una acción durante la cual emergerá una identidad que defienda los intereses de esa «identidad mayoritaria».

Por otro lado, podríamos considerar que no todos los individuos pueden identificarse con su categoría social en función de unos intereses comunes concretos. Los individuos pertenecientes a una categoría social pueden no identificarse con ésta en función de dichos intereses debido a que podrían considerar que sus intereses serán mejor defendidos por los individuos de otras categorías sociales, es decir, pueden identificarse con la categoría social por otras razones que no sean «intereses». Así, por ejemplo, un inmigrante se identifica con su colectivo de origen nacional pero no en función de que ello le beneficie con la obtención de bienes materiales y una mejor integración en la sociedad, ya que esto puede conseguirlo a través de su condición de pertenencia al colectivo con menores posibilidades económicas en la sociedad, así como, por ejemplo, una mejor integración se podría desarrollar a través de organizaciones no gubernamentales de ayuda al inmigrante y no a través de la asociación de inmigrantes. Aquí vislumbramos otra posibilidad de explicar la identidad colectiva. Volveremos después a este punto sobre identificación no en función de intereses, sino de refugio.

Pizzorno ha sido largamente criticado por autores como Touraine y J. L. Cohen. Según Cohen —respecto a la teoría de la acción dirigida a crear y mantener una identidad-, Pizzorno olvida los componentes normativos de la identidad social ${ }^{18}$, y considera que no desarrolla nuevos conceptos en la explicación de los nuevos movimientos sociales, sino diferentes etapas del círculo vital del actor social, es decir, la acción no institucional orientada al reconocimiento de identidad y la acción instrumental en pos de unos intereses.

Teniendo como referencia nuestros objetivos, nosotros estamos interesados en el primer tipo de acción; así, los razonamientos de Pizzorno — sobre el paradigma de la acción social orientada a la formación de identidades colectivas que permitan el reconocimiento de dichos actores sociales - nos parecen inicialmente válidos como hipótesis para explicar el porqué de la construcción de nuevas identidades colectivas entre inmigrantes.

Se puede concluir que, a pesar de que ambos autores - Touraine y J. L. Cohen- coinciden en que el paradigma basado en la «identidad pura» no puede dar razón suficiente de

\footnotetext{
17 A pesar de que no todo individuo puede estar igualmente afectado por dicha situación, se produce una maximización de los intereses; esto viene claramente desarrollado en las teorías racionales relativas a participación e interés.

18 Cohen también considera que la explicación a través del paradigma de la identidad de Pizzorno también excluye la dimensión estratégica del conflicto, fruto de las relaciones sociales entre adversarios (J. L. Cohen, 1985: 695).
} 
la explicación de la acción social, nosotros consideramos que, debido a que esta crítica sólo está orientada a la explicación de los nuevos movimientos sociales en función del paradigma basado en el reconocimiento de la identidad del actor social, ello no impide - como argumentábamos anteriormente- que dicha teoría pueda darnos una posible explicación del porqué de la formación de identidades colectivas, en particular, entre inmigrantes ${ }^{19}$.

La crítica de Touraine, basada en la expansión del modelo de la identidad pura, nos puede conducir a otra explicación de la formación de una identidad o, como veremos posteriormente, a una explicación del proceso que sufre una identidad colectiva desde el inicio de su formación a su total consolidación dentro de los límites de un grupo ya reconocido. Así, revisamos las teorías de Touraine, suponiendo ahora el caso en el que la acción colectiva no es una respuesta a una situación de conflicto, sino una reivindicación de conservación, de no mutación en el seno de una estructura social. Es decir, aquello que Touraine denomina «identidad defensiva», contraria a la «identidad ofensiva»20. Según este autor, el reclamo de la identidad es la acción defensiva del militante social contra las propias condiciones en la que se desarrolla su acción colectiva ${ }^{21}$. Concluyendo que la noción de identidad puede conducir a potenciar un movimiento social o bien puede estar opuesta a la participación social. Quizás el segundo punto más importante a considerar para el análisis de la formación de identidades colectivas desde las teorías de Touraine es que, dada su constatación de varias dimensiones de la acción colectiva, el autor nos induce en su estudio a tener presente al actor social en términos normativos y culturales, resumiendo que las sociedades postindustriales se representan a sí mismas como capaces de producir su propio conocimiento, su propio esquema normativo y formas socioculturales; en definitiva, se ofrecen nuevas dimensiones de identidad a los actores contemporáneos que conducen a nuevas formas de acción colectiva ${ }^{22}$.

\footnotetext{
19 Cohen considera que ninguna de las dos principales orientaciones en la explicación de la acción colectiva en los movimientos sociales es suficiente, ni el paradigma basado en la movilización de recursos ni el basado en la acción orientada al reconocimiento o creación de una identidad (J. L. Cohen, 1985). El tema, si bien apasionante, queda al margen de nuestros objetivos iniciales, aunque nos sirvamos de estas teorías sobre la acción colectiva para llegar a la explicación de la identidad colectiva como previa a toda acción.
}

20 Contraria o complementaria, porque Touraine defiende que la mayoría de los actuales movimientos sociales se caracterizan por desarrollar en un primer momento una fase defensiva o de reivindicación y posteriormente una fase ofensiva o de acción con mayor contenido político. En realidad, Touraine está considerando —en su explicación para los nuevos movimientos sociales- el paradigma basado en la orientación de éstos hacia el reconocimiento de la identidad como el paradigma basado en la estrategia de cálculos racionales (Touraine, 1993).

21 Hay que considerar que Touraine cuando mantiene que el actor —individual o colectivo- debe anteponer un principio de identidad, éste lo expresa como interés: «Si un acteur, ..., ne met avant qu'un principle d'identité, c'est-a-dire la défense de ses interêts propies...» (Touraine, 1965: 161).

22 Hemos comentado anteriormente sobre el aspecto normativo que en principio no parece lógico considerar por no existir todavía un grupo constituido; sin embargo, es evidente que debemos tener presente el aspecto cultural del actor social —del inmigrante en nuestro caso- dado que éste procede de un sistema cultural original diverso al de la sociedad de acogida, y al 
Quizás sea Touraine -entre los sociólogos contemporáneos- quien ofrezca un mayor análisis teórico del proceso de formación de identidad de los actores colectivos, que podríamos resumirlo como el paso de la identidad defensiva a la identidad ofensiva, en donde se produce también un paso de un principio simple de acción a la interacción de principios complementarios; dicho proceso puede afectar al actor, disociándolo en diversos campos de acción. En esta idea se centra la crítica sobre la identificación del movimiento social con la reivindicación de una identidad. Esta distinción, que con frecuencia se tiende a olvidar, es de gran importancia para el desarrollo de un marco teórico que permita analizar la formación de identidades colectivas orientadas a la formación de un nuevo grupo.

Melucci es otro de los autores que en ocasiones intercambia el vocablo - y su conceptode identidad con solidaridad (Melucci, 1982: 21). En general, define la identidad colectiva como un proceso de construcción de un sistema de acción, proponiendo su estudio a través de las interacciones, negociación y relaciones con el ambiente (Melucci, 1982: 52). Este autor, en el mismo sentido que los anteriormente citados, argumenta contra la explicación de la identidad en términos de interés, proponiendo que la identidad colectiva es negociada y construida a través de un proceso repetido de activación de las relaciones que mantienen los actores.

Esta visión es criticada por Calhoun, quien, como hemos mencionado anteriormente, considera importante la continua definición de interés para la reconstitución de la identidad (Calhoun, 1991). Aunque de dicho autor no debemos olvidar que sólo considera la emergencia de la identidad en un proceso de movilización, y en el que realmente no hace distinciones entre la formación de identidad individual e identidad colectiva en el transcurso de la acción ${ }^{23}$.

Así, hemos visto que en la acción que transcurre dentro de los movimientos sociales encontramos con frecuencia procesos de formación de identidades. Sin embargo, y de acuerdo con Cohen, una explicación de cómo algunos intereses colectivos emergen en el proceso de movilización no es equivalente a la formación de identidades colectivas, ideologías o solidaridades, por lo cual observamos que el mayor problema para encontrar una explica-

tiempo que, a través de dicho sistema, el individuo tiende a interpretar el nuevo sistema, también se produce una determinada acción social en la cual, y por medio de la memoria colectiva, se ponen de manifiesto esas formas socioculturales originarias. Así, en nuestro análisis la consideración del componente normativo que condiciona al actor colectivo se incluiría en su sistema cultural originario.

23 Concretamente, en el artículo sobre el movimiento de protesta estudiantil ocurrido en China en el verano del 89, la relación que establece entre «identidad» y «honor» está centrada en la formación (transformación) de la identidad individual (Calhoun, 1991). 
ción a la formación de identidades colectivas dentro de las teorías de la acción social es este punto de equiparación de conceptos ${ }^{24}$.

Concluimos que, a través de los trabajos sobre la acción colectiva, se pueden deducir inicialmente dos paradigmas que nos den una explicación de la formación de identidades colectivas entre inmigrantes: la formación de una identidad orientada a la obtención de unos intereses y dicha formación orientada a obtener una representación en un sistema del cual el colectivo portador inicialmente — sin dicha identidad - quedaba excluido. Aunque seguimos sosteniendo que el fin último de la formación de dicha identidad es poder optar a obtener unos intereses porque, si no, ¿para qué se quiere «entrar» en un sistema?

Sin embargo, como mencionamos anteriormente, el proceso de identificación podría tener como meta otros objetivos, es decir, desarrollarse en función diversa al interés. Con objeto de intentar complementar un posible modelo teórico para el análisis de la formación de las identidades colectivas pasamos a revisar los trabajos sobre etnicidad.

\section{EXPLICACIONES DESDE LOS TRABAJOS SOBRE ETNICIDAD}

Los trabajos clásicos sobre etnicidad se concentran en el estudio de la identidad étnica, sobre su naturaleza, conservación y cambios que repercuten en las fronteras del grupo étnico y sus relaciones tanto endógenas como exógenas. Dos corrientes de aproximación al fenómeno étnico han dominado la mayoría de estos estudios: Primordialistas y Circunstancialistas se han disputado la explicación de dicho fenómeno polarizando las líneas de investigación. Actualmente los llamados movimientos de resurgimiento étnico han ampliado estos estudios sobre etnicidad, proporcionándonos una mayor perspectiva en el desarrollo analítico y empírico del fenómeno. Especialmente desarrollados dentro de las teorías de la acción colectiva (Nielsen, 1985) -y más concretamente de los trabajos sobre movimientos nacionalistas o regionalistas-, los estudios sobre identidad étnica se dirigen hacia la integración en la sociología de la acción. A continuación hacemos una breve revisión de las teorías clásicas, así como de los nuevos estudios surgidos a la luz de las manifestaciones étnicas en las sociedades modernas.

\footnotetext{
24 Frecuentemente, los autores - y probablemente debido a que este no es el objetivo final de su estudio- tienden a usar arbitrariamente algunos conceptos como son identidad colectiva y solidaridad. En cualquier caso, debemos hacer constar que desde estos análisis se intenta dar una explicación de los «nuevos movimientos sociales» desde los cuales podemos extraer algunas ideas, como hemos visto para el análisis de la formación de nuevas identidades colectivas entre inmigrantes, dentro de lo que consideramos el primer paso para la formación de un grupo; aunque queremos constatar que ninguna de las identidades colectivas a considerar conduce a acciones sociales que desemboquen ni en movimientos sociales ni en identidades colectivas que queden recluidas «en los muros de una secta» (Touraine, 1993: 166).
} 
Como hemos afirmado en otros trabajos (Del Olmo, 2000), la identidad étnica se puede entender como una forma de identidad colectiva cuyos orígenes están basados en un conjunto de características sociales y culturales cuya elección no ha sido hecha por el individuo, sino que han sido transmitidas por la herencia. Sin embargo, la identificación con una identidad de carácter étnico - la autoadscripción-, y la acción social en función de ésta, es una acción voluntaria: el individuo elige esta identificación y se reconoce como miembro del conjunto portador de dicha identidad étnica. Entonces, nos preguntamos ¿por qué un individuo se identifica con cierta identidad étnica?, es decir, ¿por qué determinados rasgos de naturaleza étnica toman relevancia y llegan a constituirse como elementos diferenciadores - hacia el exterior- e identificadores —dentro de las fronteras de grupo- en un momento dado?

Desde las teorías clásicas hasta las actuales explicaciones del resurgir étnico contemporáneo

Los primordialistas han defendido la naturaleza de la identidad étnica basada en los lazos afectivos nacidos entre individuos portadores de determinados rasgos ${ }^{25}$. Estos rasgos o símbolos primordiales pueden expresarse como valores fundamentales (ej., relaciones parentales) y como símbolos externos (ej., lengua). Las acciones humanas están dirigidas por estos valores prevalentes en una sociedad. El poder emocional fruto de las relaciones basadas en la cultura común, el parentesco, la costumbre, etc., provocan una solidaridad entre los individuos que conduce a la formación de grupos étnicos. Si bien, previo al desarrollo de la solidaridad, se dan los procesos de formación de una identidad colectiva ${ }^{26}$. Hemos visto los rasgos que pueden ser englobados como los indicadores étnicos o primarios $^{27}$; los cuales se constituyen como símbolos de identificación de una determinada comunidad. Es decir, la identificación o reclamación de una identidad étnica —según los primordialistas - nace de estos componentes afectivos o uniones primarias (Geertz, 1963; Isaacs, 1975; De Vos, 1975; Keyes, 1976; etc. $)^{28}$.

25 Que, como definimos anteriormente, su principal característica es que dichos rasgos no han sido elegidos por decisión propia, sino que vienen transmitidos por la herencia, pasando de generación en generación.

26 Si bien será a partir de los estudios sobre solidaridad étnica que encontraremos algunas de las explicaciones para la formación de identidades étnicas.

27 En los estudios de etnicidad - como mencionamos en el punto anterior-se daban los tipos de rasgos que podían ser considerados como elementos de communality. Si bien existe un cierto acuerdo sobre estos rasgos, no hay una explicación exacta. Bentley ha reconocido en la «Teoría de la Práctica» de Bourdie la única respuesta a esto, extrayendo el siguiente argumento: «consciousness of affinities of interest and experiences embodies subliminal awareness of objetive communalities in practice» (Bentley, 1987: 26-29). Eder ha enfatizado — sobre la importancia del habitus en la acción colectiva en los NMSque garantiza la reproducción de estructuras tanto objetivas como subjetivas (Eder, 1985: 873).

28 Las críticas a la corriente primordialista han sido numerosas, especialmente desde la corriente circunstancialista. Por ejemplo, el primordialismo no explica cómo la gente reconoce estos rasgos comunes que en un momento dado toman importancia, 
Otros autores han considerado una dimensión intrapsíquica de la identidad (Epstein, 1978; De Vos, 1975), argumentando que existen elementos sociológicos y psicológicos presentes en la formación de la identidad. Los primordialistas han enfatizado que, en determinados contextos sociales quebrantados, la gente desorientada busca refugio en aquellos aspectos de sus vidas en donde mejor se encuentran definidos: «disoriented people refuge in those aspects of their shared lives that most fundamentally define for them who they are» (Bentley, 1987: 26). En la misma línea, Roosens ha argumentado que aquellos que se identifican con una categoría o un grupo étnico pueden encontrar una seguridad psicológica en esta identificación (Roosens, 1989: 16). Keyes también ha manifestado que la identidad étnica tiene una función psicológica, pero sólo es socialmente significativa si entra en los medios de producción, medios de expropiación de los productos de trabajo, o los medios de intercambio entre grupos son determinados por miembros de grupos no determinados por descendencia genealógica (Keyes, 1976), etc.

Podemos deducir que una explicación —nacida de estos estudios-sobre el porqué de la formación de una identidad étnica está en función de estos rasgos que generan relaciones de afecto y solidaridad; así, desde esta perspectiva podemos entender que las acciones humanas están guiadas por factores emocionales, explicando la formación de una identidad étnica como el desarrollo de una forma de refugio psicológico. Es decir, la identificación con determinados rasgos permite al individuo recrear aquellos aspectos de su vida que le proporcionan una seguridad frente a la adversidad del mundo que le rodea.

La corriente circunstancialista defiende que las acciones humanas están orientadas racionalmente hacia metas prácticas, enfatizando que la identidad étnica deriva de una manipulación de la cultura orientada a la obtención de intereses políticos o económicos; por lo tanto, el desarrollo de una identidad étnica es circunstancial.

Podíamos, por lo tanto, deducir que la formación de una identidad étnica — según esta corriente- está basada en el interés, así podríamos incluirla en nuestro estudio en el paradigma basado en el interés. Entonces, si la formación de una identidad de origen étnico es debida a la existencia de unos intereses comunes, la crítica a las teorías de la elección racional de Pizzorno podría ser válida para rebatir los orígenes de dicha identificación. Sin embargo, hacemos algunas pequeñas matizaciones. Primero, sobre la imposibilidad de hacer cálculos racionales sobre los intereses futuros de un colectivo étnico en función de su

es decir, cómo la identidad étnica es construida, porque cambia o se pierde. Entre otras críticas, Bonacich destaca que los argumentos primordialistas, por un lado, no consideran los problemas fronterizos del grupo étnico. Según esto, la acción social no es fruto de los sentimientos, del poder emocional desprendido de compartir ciertos símbolos primarios; sino que es un fiel reflejo de las decisiones sociales. Por otro lado, Bonacich expresa que el problema de la naturaleza primordial de la etnicidad es debido a que no incluye el conflicto intraétnico, es decir, el conflicto de clases dentro de una etnia, ignorando así la división horizontal de la sociedad (Bonacich, 1980). 
identidad actual; podemos establecer que los intereses de un colectivo étnico pueden permanecer invariables dado que éstos se fundamentan en rasgos culturales que son innatos al colectivo. Por lo tanto, el individuo sí puede hacer en alguna medida un cálculo racional de sus intereses futuros, dado que estos intereses — ligados a sus rasgos étnicos- pasarán de generación en generación. La defensa de la lengua, la recreación de la cultura de origen, la práctica de una religión, etc. son intereses invariables que refuerzan la solidaridad de grupo y conservan la identidad étnica ${ }^{29}$.

Pero, en este caso, el fin último que pretende la formación de la identidad colectiva es la obtención de intereses «simbólicos», o, dicho de otra manera, pretende asegurar la conservación de sus rasgos étnicos en un futuro. Pero ¿por qué razón un colectivo étnico quiere conservar dichos rasgos diferenciadores con respecto a otros grupos de la sociedad en donde se halla inserto?

Varios autores han demostrado a través de sus estudios empíricos que la etnicidad aporta ventajas estratégicas en las estructuras socioeconómicas de la sociedad. Es decir, el desarrollo de una identidad étnica permite mantener una imagen positiva y, al tiempo, demuestra que ser culturalmente diferentes es una imperiosa necesidad (Roosens, 1989); la formación de una identidad étnica como una elección estratégica que ofrece estabilidad (Bell, 1975). Laitin, reflexionando sobre la conveniencia del método comparativo para explicar las causas de la violencia en los movimientos nacionalistas - o bien su ausencia-, se centra en la posición que han jugado las diferentes clases sociales en la arena política y económica (Laitin, 1993).

Es decir, la identidad étnica convierte al colectivo en un grupo de presión, favoreciendo dicha posición a sus miembros en todos los aspectos dentro de la estructura social ${ }^{30}$.

Estos argumentos encuentran su apoyo en las explicaciones a la formación de identidades colectivas desde las teorías de la acción colectiva anteriormente expuestas ${ }^{31}$. En palabras de Touraine, la reivindicación de la identidad étnica podría manifestarse como una «identidad defensiva», es decir, donde se reivindica la conservación de los rasgos étnicos dentro de la estructura social.

\footnotetext{
29 Hay que tener en cuenta que todo sistema social es dinámico y, por lo tanto, pueden existir variaciones en la composición del grupo; recordemos la crítica de Bonacich mencionada anteriormente.

30 Diversos autores han resaltado este hecho: Glazer y Moynihan, Patterson, Cohen, etc.

31 Hay que hacer una distinción: mientras que Glazer y Moynihan hablan de «grupo de presión» relativo a interés, Touraine lo hace con orientación al reconocimiento de una identidad.
} 
Englobando los diversos análisis, la explicación para la formación de la identidad étnica se podría encontrar dentro del modelo basado en la identidad pura. Así, la identificación con características étnicas puede ir en pos de un reconocimiento. Es decir, los rasgos de naturaleza étnica se convierten para un colectivo en diferenciadores étnicos cuando entran en contacto con un colectivo -o varios colectivos- que diverge en sus formas culturales y su campo semántico relativo. El sistema de valores, la cultura, la lengua, las costumbres sociales, etc., o cualquiera de los rasgos mencionados anteriormente toman relevancia por primera vez para el colectivo portador porque otorgan una frontera de grupo a dicho colectivo.

Dicha identidad étnica podría dar lugar a dos circunstancias:

Primera, que la posesión de estos rasgos impida a los miembros de este colectivo entrar en la estructura social de la cual difiere culturalmente. Desarrollando una «identidad ofensiva» que les permita la equiparación socioeconómica en el sistema.

Segunda, que inmerso un colectivo — diferente étnicamente- en la anonimia de la sociedad mayoritaria, dicho colectivo adscriba dicha identidad étnica, permitiéndole de esta manera obtener una posición relevante, de defensa de sus intereses, es decir, desarrolle una “identidad defensiva»32. Igualmente se puede aplicar cuando conviven varios colectivos diferentes étnicamente, como sucede en áreas de intensa inmigración; así, algunos autores contemporáneos — por ejemplo, Olzak - afirman en sus trabajos sobre el conflicto étnico que niveles elevados de rivalidad entre grupos étnicos incrementan la participación en la acción colectiva (Olzak, 1992).

En cualquiera de los dos casos, a través de la identificación con sus rasgos étnicos, el colectivo obtiene un reconocimiento. Aquí observamos que el modelo basado en la identidad pura puede ser aplicado a la formación de la identidad étnica, pues a través de ésta - de su formación - los individuos pueden entrar en un sistema que difiere culturalmente -étnicamente- o bien conservar su reconocimiento (Pizzorno, 1983, 1989) ${ }^{33}$.

32 En el punto anterior quedaron explicadas las teorías de Touraine sobre la formación de las identidades defensivas y ofensivas.

33 Los estudios sobre identidad étnica dentro de la corriente circunstancialista han tomado muy diferentes aspectos, siendo Cohen de los primeros en criticar que el modelo de categorías étnicas como organizaciones vessels, es decir, fijas y estáticas, no se correspondía con el dinamismo de etnicidad, profundamente conectado con las relaciones políticas y económicas. Así, surgieron estudios sobre las incidencias del sistema capitalista en el desarrollo de las identidades étnicas (ej., Wallerstein), las relaciones entre etnicidad y estratificación de las clases sociales, ligado con teorías de poder (ej., Van den Berghe, Despres, etc.), estudios sobre las relaciones entre modernidad y etnicidad, etc. 
Desde las actuales explicaciones del resurgir étnico contemporáneo

Las teorías actuales sobre identidades étnicas nacen en el seno de estudios sobre nacionalismo y su resurgencia en las sociedades desarrolladas ${ }^{34}$, sobre el resurgir de la solidaridad étnica en una sociedad en donde se pensaba décadas atrás que las diferencias étnicas se habrían erradicado a consecuencia de la homogeneidad cultural (competition model-Hannan, 1979-).

Algunos de estos estudios — sobre el resurgir étnico- en las sociedades desarrolladas tienden a considerar éstos dentro de los problemas de la acción colectiva, predominando

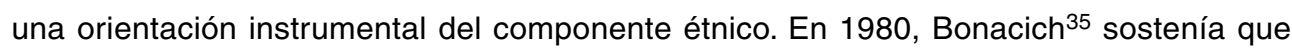
existen dos importantes bases para la identificación con una comunidad: la solidaridad basada en los intereses de clase y aquella basada en la etnicidad. Defendiendo - junto con otros autores- desde una corriente estructuralista que los factores económicos juegan un importante papel en la potenciación o disolución de los lazos étnicos (Bonacich, 1980).

Ligado con las teorías de la acción colectiva, otros autores consideran dos principales bases en función de las cuales se produce una movilización: la pertenencia a una determinada clase y la pertenencia a una identidad étnica. Parece ser que existe un común acuerdo sobre los dos tipos de bases que condicionan la identidad del actor colectivo en la sociedad postindustrial: etnicidad y clase social.

Nielsen sostiene que la etnicidad resulta ser una base más conveniente para la movilización que la división de clases. Así, este autor ha intentado crear un modelo a partir de otros dos para explicar la solidaridad étnica ${ }^{36}$. Ambos partían de una premisa que —como mencionamos anteriormente - parece no haberse cumplido: la modernización traería un descenso de las distinciones étnicas a consecuencia del incremento de la homogeneidad cultural. Sin embargo, en las sociedades más avanzadas el resurgir étnico — principalmente regionalista o nacionalista - es un hecho constatable. Si el modelo de la etnicidad reactiva (Hechter, 1975) ${ }^{37}$ exponía que la solidaridad étnica es una reacción de la periferia contra la

\footnotetext{
34 De todos ellos revisaremos algunos que nos ofrezcan alguna explicación sobre el porqué de la formación de las identidades étnicas.

35 La obra se centra en un tipo concreto de grupo étnico, una minoría de intermediarios japoneses. A través de la cual argumenta sobre el componente económico de la solidaridad étnica. Ver Bonacich (1980).

36 En realidad, en los estudios contemporáneos no se analiza la formación de la identidad étnica, sino el porqué del desarrollo de una solidaridad étnica a partir de una identidad que se supone ya formada.

37 Expuesto por primera vez en 1975 a través de las teorías del colonialismo interno de Hechter y posteriormente revisado por el mismo autor diez años después. Ver Hechter $(1975,1985)$ y Hechter \& Levi (1985).
} 
explotación del centro, el modelo competitivo (Hannan, 1979) exponía que la modernización afecta a los grupos étnicos homogéneamente, pudiendo competir y alcanzar posiciones semejantes. Entre las varias conclusiones de Nielsen, destaca que las tendencias sociales asociadas con la industrialización pueden afectar a los grupos en los cuales la etnicidad puede ser más conveniente para la movilización. La diversidad cultural decrece con la modernidad, al tiempo que se incrementa el promedio de grupos distinguibles sobre bases culturales. Las razones son, entre otras, el solapamiento entre la solidaridad basada en la etnicidad o en la clase. La diferenciación de roles implica una disminución de los intereses comunes; como resultado, tiende a ser más funcional la movilización de los recursos basada en la etnicidad ${ }^{38}$.

Melucci, que inicialmente también explica la identidad basada en criterios de interés, reforzando las teorías del "colonialismo interno», destaca que en la sociedad contemporánea se ha producido una coincidencia entre la pertenencia a una clase económicamente desfavorecida y la pertenencia a una etnia que difiere de la mayoría ${ }^{39}$. Destaca, por último, Melucci que la identidad étnica - la etnicidad - se ha convertido en el único instrumento con el que una minoría puede oponerse al monopolio cultural del grupo dominante. La identidad étnica tiende a una «identidad simbólica» (Gans, 1979; Melucci, 2001). Completa la idea - compartida por Nielsen - de que la identidad étnica genera un tipo de solidaridad con un patrimonio histórico que proporciona, desde los elementos étnicos, recursos organizativos para exponer conflictos. Por último, como vimos anteriormente, Melucci —dentro de la explicación de la formación de una identidad para obtener el reconocimiento- expone que, al tiempo que la identidad étnica permite una organización de los intereses, ésta permite una fuerte diferenciación, implicando un grado de competición elevado (Melucci, 1982; Melucci y Diani, 1983). Es más, Melucci argumenta sobre el resurgir de la solidaridad étnica como una fuerza autónoma, en donde surgen demandas orientadas a la defensa de la diversidad, conduciendo a establecer nuevas relaciones entre grupos (Melucci, 2001).

Durante la década de los ochenta ha habido una importante aportación para la explicación del desarrollo de la solidaridad de grupo. Entre otros, cabe destacar - como mencionamos anteriormente - el trabajo de Hechter. A través de su artículo «Internal Colonialism Revisited», aparentemente demuestra que las solidaridades culturales incrementan más la solidaridad de grupo que los intereses materiales, diciendo que la solidaridad depende más de la dimensión de la división cultural del trabajo porque la interacción de estatus iguala dentro de las minorías y proporciona un incremento de intereses entre los miembros. Si la

\footnotetext{
38 Aunque Nielsen en su estudio también destaca que la etnicidad que resurge actualmente parece distinta a la de tiempos anteriores (Nielsen, 1985).

39 Este punto resulta significativo en nuestro caso de estudio ya que, efectivamente, los grupos inmigrantes son una clara muestra de ello. Melucci también ha destacado a este respecto que algunos conflictos étnicos de la década de los ochenta no tienen por objeto el control de un área territorial.
} 
solidaridad de grupo ha venido explicándose tradicionalmente desde las corrientes normativista, estructuralista y racionalista, Hechter —en su obra de 1987- dice que el actor se encuentra limitado, por lo que no es suficiente que existan unos intereses comunes para desarrollar solidaridad, sino que son necesarias las divisiones culturales segmentales más las jerarquías que proporcionan las divisiones culturales del trabajo. Concluyendo que para desarrollar una solidaridad de grupo son necesarios tanto la dependencia entre sus miembros como la capacidad de control (Hechter, 1985, 1987).

Más recientes son los trabajos de algunos autores como Olzak (1991, 1992, 2001), Olzak y Nagel (1986) y Laitin $(1989,1991,1993)$, etc., en los cuales se pueden encontrar nuevas reflexiones sobre protesta social y conflicto étnico y racial.

Como vemos, todos estos trabajos dan una explicación de las consecuencias de la modernidad sobre la solidaridad étnica o bien sobre el resurgir de la etnicidad en todas sus dimensiones en la sociedad postindustrial. Sin embargo, poco ofrecen del porqué de la formación de nuevas identidades étnicas, aunque cabe destacar algunos rasgos de lo anteriormente expuesto importantes para explicar la formación de una identidad étnica como es la existencia de un pasado, una memoria colectiva, etc. Wallerstein también argumentó esto tiempo antes: la identidad étnica permite hacer reclamaciones basadas en el pasado contra procesos racionales manipulados por el presente (Wallerstein, 1979: 78).

En general, el pasado compartido por un grupo de individuos incrementa la socialización, pudiendo conducir a crear nuevos modelos de comportamiento; la socialización a través de un colectivo étnico pone en contacto a individuos con un conjunto de normas y valores originalmente comunes, pudiendo éstos modificarse conjuntamente.

Otro aspecto que destacamos de estos estudios sobre el resurgir étnico en la sociedad contemporánea es afirmar que, efectivamente, la identidad étnica sí depende de unas circunstancias concretas. Afirmamos esto porque si en la sociedad postindustrial se están produciendo diversos movimientos étnicos y se constata la presencia de partidos etnorregionalistas, quiere decir que determinados rasgos de este tipo de sociedad sí favorecen el desarrollo de estas identidades. Touraine ha estudiado y definido esta sociedad postindustrial o «programada» como aquella en la que «la producción y la difusión masiva de los bienes culturales ocupan el lugar central que había sido el de los bienes materiales en la sociedad industrial» (Touraine, 1993: 313). Estos argumentos nos pueden dar una explicación del porqué del desarrollo de movimientos étnicos, dado que esta sociedad gestiona los bienes culturales para influir en los valores y comportamientos. Como nuevas formas de control social, también se pueden modelar nuevas formas de identidad dentro de un colectivo étnico tomando su producción cultural propia. Por lo tanto, nos preguntamos si la formación 
de una identidad étnica entre inmigrantes también depende de esta circunstancia, es decir, de su inserción en una sociedad postindustrial, y, llegados a este punto y continuando con la revisión de la literatura más actual sobre los nuevos movimientos sociales, nos vemos obligados a reflexionar sobre la necesidad de establecer un nuevo marco de referencia -abandonando el esquema de la sociedad postindustrial- que nos sitúe en la sociedad de la gobalización, en donde la construcción de la identidad parece emerger principalmente como un sistema de defensa, de refugio en una «sociedad del riesgo» (Lasch, 1996) ${ }^{40}$.

Como hemos venido expresando, nuestro objetivo es intentar conocer por qué esas determinadas características -o indicadores étnicos - llegan a ser relevantes para el individuo que las posee hasta identificarse con ellas; por ello queremos hacer una última reflexión de carácter analítico: consideramos que la identidad étnica sólo puede ser manifestada a través de formas culturales inherentes a la categoría étnica original; por lo tanto, será necesario analizar esas formas culturales y su campo de significados ${ }^{41}$. Como ha apuntado Smith, será básico observar el complejo myth-symbol y los mecanismos de difusión, lo cual imprime el carácter de la identidad étnica, teniendo en cuenta que los mitos pueden tener orígenes temporales y espaciales (Smith, 1991) ${ }^{42}$.

\section{CONCLUSIONES}

Hemos visto desde la interpretación del resurgir étnico dos posibles paradigmas para explicar el porqué de la formación de identidades colectivas, los cuales son compartidos desde las teorías de la acción colectiva: el paradigma basado en el interés y el paradigma basado en el reconocimiento. Desde los trabajos sobre etnicidad extraemos un tercer paradigma: el paradigma del refugio psicológico. Es decir —como mencionamos en el punto anterior-, los individuos que comparten unas características determinadas desarrollan una identidad, se identifican con estos determinados rasgos cuando se encuentran con circunstancias de ruptura y necesitan de un entorno que les proporcione seguridad psicológica.

Los inmigrantes a través de sus previas experiencias y conocimientos interpretan el nuevo sistema social. Adaptarán su estructura cognitiva y normativa, esto constituirá el proceso

\footnotetext{
40 Dicha reflexión, si bien nos parece obligada y al mismo tiempo apasionante, será tratada en otro trabajo debido a la limitación de espacio, así como al objetivo principal de estas páginas.

41 Por ejemplo, el estudio de los sistemas de símbolos de un colectivo inmigrado como expresión de los límites de una identidad.

42 Este punto puede ser significativo para el estudio de un colectivo de origen inmigrante. Consideramos que la formación de identidades entre inmigrantes requiere una formación de símbolos transitorios. Así como tener en cuenta los distintos aspectos que ayudan a formar y mantener una identidad. En este sentido, por ejemplo, Smith postula que éstos son la sedentarización y la nostalgia, junto con la religión organizada y el estado de entreguerra (Smith, 1991).
} 
de resocialización, que a nivel individual provocará una interiorización de las normas y una modificación de los valores ${ }^{43}$.

Las diferencias culturales y las circunstancias materiales son factores importantes en estos procesos de interacción social. Respecto a los inmigrantes, el primer factor es claro: las diferencias culturales son obvias, más o menos acentuadas pero que marcan fronteras ${ }^{44}$. Entre estos factores cabe destacar la lengua, como punto primordial para iniciarse el proceso de socialización. Así como otros que afectan a su sistema de valores y costumbres; por ejemplo, la religión, o más exactamente si proceden de una sociedad secularizada o no, etc. Las carencias económicas podrían englobar a los inmigrantes en las capas desfavorecidas de la sociedad de acogida ${ }^{45}$; sin embargo, es una situación más que comparten y que conduce a generar solidaridad e intereses comunes.

Según lo anteriormente expuesto, cuando un colectivo inmigrante se encuentra desarraigado a consecuencia de la emigración, la construcción de una identidad colectiva puede tener su explicación en la búsqueda de refugio psicológico ${ }^{46}$, en cuyo caso las fronteras de grupo están bien definidas y son difíciles de traspasar, la estructura interna del grupo está bien estructurada y las relaciones con el exterior también están perfectamente definidas. Otra posible explicación está determinada por las expectativas del colectivo inmigrante en cuanto a la adquisición de ciertos bienes materiales, en cuyo caso la identidad desarrollada podría estar cimentada en la clase, o en el tipo de actividad laboral —pudiendo aglutinar a inmigrantes procedentes de distintas nacionalidades o diferentes étnicamente-, o bien desarrollarían una identidad étnica a través de la cual reivindicarían sus objetivos ${ }^{47}$.

43 La formación de una identidad colectiva dependerá fundamentalmente de los espacios de interacción social del inmigrante. Un espacio clave para la interacción social de estos individuos $-\mathrm{y}$ por consiguiente en el desarrollo de identidades colectivas- son las organizaciones creadas por los propios inmigrantes.

44 En estas migraciones contemporáneas las diferencias abarcan aspectos no sólo relativos a la lengua, cultura, rasgos físicos, etc., sino también a una serie de vivencias sociales y políticas que determinan las expectativas de vida del individuo.

45 Se dan una serie de circunstancias que conducen a una emigración: el factor económico es importante pero más desde el punto de vista de las posibilidades de ascenso y estabilidad socioeconómica, por lo que la situación social y política de la sociedad emisora es decisiva.

\footnotetext{
46 Pueden desarrollar una identidad basada en las relaciones primarias - la familia, los amigos, etc.-, pueden desarrollar una identidad étnica que les aporte en alguna medida aquellos elementos de su sociedad anterior, o bien una identidad religiosa que les proporcione un sentimiento de protección.

47 La diferencia de una u otra dependería fundamentalmente de la relación que el colectivo de origen inmigrante mantenga con la sociedad de acogida; la identidad cívica implica una asimilación en dicha sociedad, lo cual dependerá también de las condiciones que ofrezcan dichas sociedades de acogida a los colectivos inmigrantes. Sin embargo, el desarrollo de una identidad primaria conduce más al mantenimiento de grupos marginales, reflejo de la falta de posibilidades que puede ofrecer dicha sociedad para la integración de los colectivos de origen inmigrante, o a las dificultades que presentan estos colectivos en sus relaciones sociales.
} 
Por último, la explicación para la construcción de identidades colectivas entre inmigrantes podría ser la búsqueda de reconocimiento: si un colectivo inmigrante se siente marginado en la sociedad de acogida, es decir, carece de un reconocimiento que le impide participar en el sistema - recordando el identity oriented paradigm - estos individuos podrían utilizar esos mismos rasgos por los cuales son excluidos potenciando una identidad étnica, o bien podrían desarrollar una identidad de clase que les permitiera alcanzar una vía política de integración social.

La resolución de nuestra hipótesis nos conduce a clarificar que, respecto al segundo paradigma - la construcción identitaria en función del interés-, consideramos que en los colectivos de inmigrantes dichos beneficios materiales podrían ser obtenidos a través de estructuras organizativas propias de la sociedad de inmigración -asociaciones de ayuda al inmigrado, organizaciones no lucrativas de ayuda a los más desfavorecidos socieconómicamente- y, una vez obtenidos, no tendría sentido seguir potenciando una identidad, colectiva. La persecución de bienes públicos que afectan al conjunto de la población inmigrante tampoco es la razón para el desarrollo de una acción social que construya identidad, dado que estos bienes beneficiarían por igual y la presencia del «hombre indiferente» sería inevitable; de hecho, hemos constatado empíricamente que, tras un periodo de afiliación a las asociaciones de inmigrantes, los individuos consideran que pueden obtener lo mismo sin pagar la cuota fijada, por lo que la permanencia en la asociación corresponde a otras razones. Así, afirmamos que un colectivo inmigrante que perdura en el tiempo como grupo persigue unos intereses de tipo simbólico.

Si constatamos que los inmigrantes pueden hacer un cálculo racional de sus intereses futuros cuando éstos se fundamentan en su cultura de origen, sin embargo, no consideramos que el fin de la construcción de su identidad sea la obtención de esos intereses. Estos intereses pretenden conservar los rasgos de la cultura de origen porque les confiere un reconocimiento como colectivo, incluso con el paso del tiempo, cuando hayan superado las desventajas sociales, económicas y jurídicas que les definían como inmigrantes. Por lo tanto, la construcción identitaria por parte de un colectivo inmigrante tiene como fin último el reconocimiento. A través de este reconocimiento, los miembros de un colectivo inmigrante pueden participar de la estructura social de la cual difieren culturalmente y les permite una equiparación con otros miembros del sistema, de la sociedad de acogida. Por otra parte, evitan la asimilación, la anonimia en la sociedad de acogida. Las asociaciones de inmigrantes se convierten en actores sociales, cuyas acciones están orientadas a la formación de una identidad colectiva que permita el reconocimiento de dichos actores sociales. Las características que definen las fronteras de su identidad deben afectar a las relaciones sociales del inmigrante en su nuevo contexto de inmigración, al tiempo que deben permitir una estructura organizativa que se constituya en representante social del colectivo inmigrante 
reconocido por la sociedad de acogida. Además, dichas características deben representar para el inmigrante aquellos aspectos de su vida en donde mejor se encuentre definido, dado que en un proceso migratorio el contexto social originario se ha quebrantado y el inmigrante busca refugio (Epstein, 1978; De Vos, 1975); evidentemente, aquella identificación que les aporta cierta seguridad psicológica nace de la identificación con los rasgos primarios que generan relaciones de afecto y solidaridad porque ello conducirá a construir un grupo homogéneo y estable. Por medio de esa identificación se toma consciencia de esos rasgos comunes y de la necesidad de que éstos sean reconocidos por aquellos que no los poseen.

Por lo tanto, afirmamos que los paradigmas basados en la representación y el basado en el refugio psicológico, para explicar la construcción de identidad colectiva entre inmigrantes, son complementarios. Concluimos que el paradigma del refugio psicológico nos explica por qué esos determinados rasgos y no otros construyen las fronteras de su identidad y en qué circunstancias de desarraigo social toman relevancia, y el paradigma de la identidad pura nos explica el porqué de esa construcción identitaria.

\section{REFERENCIAS BIBLIOGRÁFICAS}

ADAM, H. (1984): «Rational Choice in Ethnic Mobilization; A Critique», en International Migration Review, 18, pp. 377381.

BELL, D. (1975): «Ethnicity and Social Change», en N. Glazer y D. P. Moynihan, Ethnicity: Theory and Experience (Cambridge: Harvard University Press).

BENTLEY, G. C. (1987): «Ethnicity and Practice», en Society for Comparative Study of Society and History, pp. 24-55.

BONACICH, E., y MODELL, J. (1980): The Economic Basis of Ethnic Solidarity: Small business in the Japanese American Community (Berkeley \& Los Angeles: University of California Press).

CALHOUN, C. (1991): «The Problem of Identity in Collective Action», en J. Huber (ed.), Macro-Micro Linkages in Sociology (London, Newbury Park and New Delhi: SAGE), pp. 51-75.

COHEN, J. L. (1985): «Strategy or Identity: New Theoretical Paradigms and Contemporary Social Movements», en Social Research, vol. 52, n. ${ }^{\circ} 4$ (Winter), pp. 663-716.

COLEMAN, J. (1990): Foundations of Social Theory (Cambridge, Massachusetts, and London: The Belknap Press of Harvard University Press).

DE VOS, G. (1975): «Ethnics Pluralism:Conflict and Accomodation», en G. De Vos y L. Romanucci-Ross (eds.), Ethnic Identity (California: Mayfield), pp. 5-41.

DEL OLMO VICÉN, N. (2000): Hacia una explicación de la construcción de identidades colectivas entre inmigrantes (Bilbao: Congreso Vasco de Sociología).

DICKIE-CLARK, H. F. (1984): «The Debate over the Theory of Rational Choice», en International Migration Review, 18, 1, pp. 164-170. 
EDER, K. (1985): «The "New Social Movements": Moral Crusades, Political Pressure Groups, or Social Movements», en Social Research, vol. 52, n. ${ }^{\circ} 4$ (Winter), pp. 867-890.

EPSTEIN, A. L. (1978): Ethos and Identity: three studies in ethnicity (London: Tavistock).

GAMSON, W. A. (1975): The Strategy of Social Protest (Homewood III: The Doorsey Press).

GANS, H. J. (1979): «Symbolic Ethnicity: the future of ethnic groups and cultures in America», en Ethnic and Racial Studies, $2, \mathrm{n} .^{\circ} 1$.

GEERTZ, C. (1963): «The Integrative revolution: Primordial Sentiments and Civil Politics in the New States», en C. Geertz (ed.), Old Societies and New States (New York: Free Press), pp. 105-157.

HANNAN, M. T., y MEYER, J. W. (1979): National Development and the World System. Educational, Economic, and Political Change, 1950-1970 (Chicago \& London: The University of Chicago Press).

HECHTER, M. (1975): Internal Colonialism: the Celtic fringe in British National Development, 1536-1966 (London: Routledge \& Kegan Paul).

- (1985): «Internal Colonialism Revisited», en Edward A. Tiryakian y Ronald Rogowski (eds.), New Nationalisms of the Developed West (London: George Allen \& Unwin), pp. 17-26.

- (1987): Principles of Group Solidarity (Berkeley-Los Angeles-London: University of California Press).

HECHTER, M.; FRIEDMAN, D., y APPELBAUM, M. (1984): «A Theory of Ethnic Collective Action», en International Migration Review, vol. 16, n. ${ }^{\circ}$ 2, pp. 412-434.

HECHTER, M., y LEVI, M. (1985): «A Rational Choose Approach to the Rise and Decline of Ethnoregional Political Parties", en Edward A. Tiryakian y Ronald Rogowski (eds.), New Nationalisms of the Developed West (London: George Allen \& Unwin), pp. 128-146.

HOLZNER, B. (1983) (1978): «La Costruzione di Attori Sociali. Saggio sulle Identità Sociali», en L. Siolla (ed.), Identità: Percorsi di Analisi in Sociologia (Torino: Rosenberg \& Sellier).

ISAACS, H. R. (1975): «Basic Group Identity: The idols of the tribe», en N. Glazer y P. Moynihan (eds.), Ethnicity: Theory and Experience (Cambridge, Massachusetts \& London: Harvard University Press), pp. 29-52.

JACKSON, R. H. (1984): «Ethnicity», en G. Sartori (ed.), Social Sciences Concept. A systematic Analysis (Beverly Hills: SAGE Pub.), pp. 205-233.

KEYES, Ch. (1976): «Towards a New Formulation of the Concept of Ethnic Group», en Ethnicity, 3.3, pp. 202-13.

KLANDERMAS, B. (1989): “Grievance Interpretation and Sucess Expectations: the social construction of Protest», en Social Behaviour, n. ${ }^{\circ}$, pp. 113-125.

LASCH, Ch. (1996): The Revolt of the elites and the betrayal of democracy (New York, etc.: W. W. Norton).

McADAM, D. (1988): «Micromobilization Contexts and Recruitment to Activism», en B. Klandermas, H. Kriesi y Tarrows (eds.), From Structure to Action: Comparing social movement research across culture, vol. 1, ISMR (Greenwich: JAI Press).

LAITIN, D. D. (1993): National Revivals and Violence, Estudio/Working Paper 1993/49 (Madrid: Center for Advanced Study in the Social Sciences of The Juan March Institute).

MARTELLONE, A. M. (1991): «Trent'anni di studi su Etnia e Politica», en E. Fano, Una e Divisibile (Firenze: Ponte alle Grazie), pp. 161-195. 
MELUCCI, A. (1982): L’Invenzione del Presente. Movimenti, identità, bisogni individuali (Bologna: II Mulino).

- (2001): Vivencia y Convivencia.Teoría social para una era de la información (Madrid: Trotta).

MELUCCI, A., y DIANI, M. (1983, 1991): Nazioni senza Stato. I movimenti etnico-nazionali in Occidente (Torino: Loescher).

NIELSEN, F. (1985): «Toward a Theory of Ethnic Solidarity in Modern Societies», en American Sociological Review, vol. 50 (april), pp. 133-149.

OLSON, M. (1968): The Logic of Collective Action. Publics goods and the theory of groups (Cambridge: Harvard University Press).

OLZAK, S. (1992): The Dynamics of Ethnic Competition and Conflict (Stanford: Stanford University Press).

PIZZORNO, A. (1977): «Scambio Politico e Identità Collettiva nel conflitto di Classe», en C. Crouch y A. Pizzorno, Conflitti in Europa. Lotte di classe, sindicati e stato dopo il '68 (Etas Libri), pp. 407-433.

- (1981): «Interests and Parties in Pluralism», en S. Berger (ed.), Organizing Interests in Western Europe. Pluralism, corporatism, and the transformation of politics (Cambridge: Cambridge University Press), pp. 247-284.

- (1983): «Identità e Interesse», en L. Sciolla (ed.), Identità. Percorsi di Analisi in Sociologia (Torino: Rosenberg \& Sellier), pp. 139-154.

- (1989): «Algún otro tipo de alteridad: una crítica a las teorías de la elección racional», en Sistema. Revista de Ciencias Sociales, n. ${ }^{\circ} 88$, pp. $27-42$.

ROOSENS, E. E. (1989): Creating Ethnicity, the process of ethnogenesis (Newbury Park, London and New Delhi: SAGE Publications).

SMITH, A. D. (1991): «The Nation: Invented, Imagined, Reconstructed?», en Millenium: Journal of International Studies, vol. 20, n. ${ }^{\circ}$ 3, pp. 353-368.

TILLY, C. (1978): From Mobilization to Revolution (Reading, Massachusetts: Addison-Wesley Publishing Company).

TOURAINE, A. (1965): Sociologie de l'Action (Paris: Seuil).

- (1993): Crítica de la Modernidad (Madrid: Ed.Temas de Hoy).

WALLERSTEIN, I. (1988): «La Construction des Peuples: Racisme, Nationalisme, Ethnicité», en I. Wallerstein y E. Balibar, Race, Nation et Classe les identities ambigues (Paris: Editions La Decouverte), pp. 95-116. 


\section{ABSTRACT}

The aim of this article is to establish a valid framework of analysis for finding an answer to reasons underlying identity construction among immigrants. In order to do this, we shall reflect on works that consider the processes of formation of collective identities in different theoretical traditions, and whose literature is mainly nourished by studies on collective action and works on ethnicity, including in these latter the works aimed at explaining contemporary ethnic resurgence. We conclude the article by extracting three possible paradigms for explaining the reason for the formation of collective indentities among immigrants: first, the rationalist paradigm that explains the construction of identities according to the existence of common interests. The paradigm of representation which explains identity construction as a way of recognition that allows participation of the immigrant group in the system of the receiving society. Thirdly, the paradigm of psychological refuge for explaining identity construction as a response to a situation of being unprooted, which is a consequence of the migratory process. The main hypothesis is that identity construction in the heart of groups with an immigrant origin finds its motive in the search for recognition within the receiving society.

Key words: Collective Identity, Immigrants, Ethnic Identity. 